\title{
Development and Validation of A Spectrophotometric Method for Quantification and Dissolution Studies of Glimepiride in Tablets
}

\author{
MADHUSUDHANAREDDY INDURI*, BHAGAVAN RAJU M $^{2}$, RAJENDRA PRASAD \\ $\mathrm{Y}^{3}$ AND PAVANKUMAR REDDY $\mathrm{K}^{2}$ \\ ${ }^{* 1}$ Department of Pharmaceutical Chemistry, Malla Reddy College of Pharmacy, \\ Maisammaguda, Dhulapally, Secunderabad 500014 \\ ${ }^{2}$ Department of Pharmaceutical Chemistry, C.M. College of Pharmacy, Maisammaguda, \\ Dhulapally, Secunderabad 500014 \\ ${ }^{3}$ Department of Pharmaceutical Chemistry, A. U. College of Pharmaceutical Sciences, \\ Andhra University, Visakhapatnam 530003, Andhra Pradesh, India
}

\section{E-mail:imsreddychem@yahoo.com}

\section{Received 10 July 2011; Accepted 20 September 2011}

\begin{abstract}
The objective of present study was to develop and validate an analytical method for quantitative determination and dissolution studies of glimepiride in tablets. The glimepiride shows absorption maxima at $225 \mathrm{~nm}$ and obeyed Beer's law in the range of $6.0-14.0 \mu \mathrm{g} / \mathrm{mL}$. The limit of detection and limit of quantitation were 0.06 , and $0.17 \mu \mathrm{g} / \mathrm{mL}$ respectively. Percentage recovery of glimepiride for the proposed method ranged from 99.32 to $100.98 \%$ indicating no interference of the tablet excipients. It was concluded that the proposed method is simple, easy to apply, economical and used as an alternative to the existing spectrophotometric and non-spectrophotometric methods for the routine analysis of glimepiride in pharmaceutical formulations and in vitro dissolution studies.
\end{abstract}

Key words: Glimepiride, Dissolution studies, Tablets, UV Spectrophotometry.

\section{Introduction}

Chemically, Glimepiride, shown in Figure 1, is 1-\{(p-[2-(3-ethyl-4-methyl-2-oxo-3pyrroline-1-carboxamide) ethyl] phenyl) sulfonyl $\}-3$ - (trans-4-methylcyclohexyl) urea, is $3^{\text {rd }}$ generation sulfonylurea derivative used for the treatment of type II diabetes mellitus ${ }^{1}$. A survey of pertinent literature revealed that few liquid chromatography ${ }^{2,3}$ and derivative spectrophotometry ${ }^{2,4}$ methods has been developed for the determination of glimepiride in pharmaceutical formulations. Liquid chromatography-electrospray ionization tandem mass spectrometry ${ }^{5}$ method has been developed for the quantification of glimepiride in human 
plasma. Spectrophotometry ${ }^{6,7}$ and Liquid chromatography ${ }^{8,9}$ methods have also been developed for the estimation of glimepiride in combination with other drugs in pharmaceutical formulations. Most of these are either time consuming; involve expensive instrumentation or the use of excess organic solvents, dimethyl formamide is used as a solvent in the reported UV spectrophotometry $\operatorname{method}^{4}$, which is expensive and carcinogenic. Dissolution studies have emerged in the pharmaceutical field as a very important tool based on the fact that for a drug to be absorbed and available to the systemic circulation, it must previously be solubilized. Therefore the dissolution studies are used not only to assess batch-to-batch consistency of drug release from solid dosage forms, but they are also essential in several stages of formulation development, for screening and proper assessment of different formulations. Moreover, the in vitro dissolution studies obtained from dissolution rate profile has been used for the successful characterization of the in vivo behavior of drugs ${ }^{10}$. The aim of the present work is to develop and validate a simple UV spectrophotometric method to be applied for the quantification and dissolution studies of glimepiride in tablets, which therefore serves as a tool for the quality control of pharmaceutical dosage forms.



Figure 1: Chemical Structure of Glimepiride.

\section{Materials and Methods}

\section{Instrumentation}

A Labindia $3000^{+}$UV-Visible Spectrophotometer with spectral bandwidth of $2.0 \mathrm{~nm}$ and wavelength accuracy of $\pm 0.5 \mathrm{~nm}$ with automatic wavelength correction and a pair of $10 \mathrm{~mm}$ quartz cells were used for the absorbance measurements connected with UVWIN version 5.2.0 software. The dissolution studies were performed on Electro lab, TDT-08L USP dissolution apparatus.

\section{Materials}

The glimepiride (assigned purity 99.68\%) was kindly supplied as a gift sample by Matrix Laboratories Ltd., Hyderabad, India. All chemicals and solvents used in the spectrophotometric analysis were of analytical reagent grade obtained from Rankem Ltd, India.

\section{Methods}

\section{Preparation of standard solution}

Standard stock solution $(100 \mu \mathrm{g} / \mathrm{mL})$ was prepared by transferring $10 \mathrm{mg}$ of glimepiride into a $100 \mathrm{~mL}$ volumetric flask, $30 \mathrm{~mL}$ of $0.1 \mathrm{M}$ sodium hydroxide was added, and the mixture was sonicated to dissolve and make up the volume with methanol. Aliquots of these standard solution was transferred using A-grade bulb pipette into $100 \mathrm{~mL}$ volumetric flasks and made up to volume with methanol to get final concentration of $6.0-14.0 \mu \mathrm{g} / \mathrm{mL}$. 


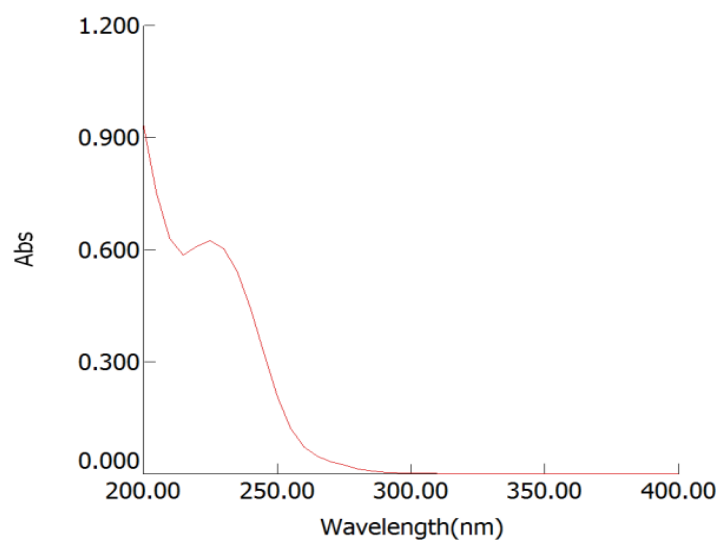

Figure 2. UV-spectra of glimepiride against methanol as blank.

Table 1. Calibration data of the proposed method.

\begin{tabular}{ll}
\hline Parameters & Results \\
\hline$\lambda_{\max }(\mathrm{nm})$ & 225 \\
Beer's law range $(\mu \mathrm{g} / \mathrm{mL})$ & $6-14$ \\
Molar extinction coefficient $(1 / \mathrm{mol} / \mathrm{cm})$ & 0.06159 \\
Sandell's sensitivity $\left(\mu \mathrm{g} / \mathrm{cm}^{2}\right)$ & 0.016364 \\
Limit of detection $(\mu \mathrm{g} / \mathrm{mL})$ & 0.06 \\
Limit of quantitation $(\mu \mathrm{g} / \mathrm{mL})$ & 0.17 \\
Regression equation & \\
Intercept (a) & 0.1621 \\
Slope (b) & 0.0438 \\
Correlation coefficient $\left(\mathrm{r}^{2}\right)$ & 0.9993 \\
\hline
\end{tabular}

Table 2: Recovery of glimepiride standard solution added to sample solution analyzed by proposed method.

\begin{tabular}{llllll}
$\begin{array}{l}\text { Amount } \\
\text { (\%) of drug } \\
\text { added to } \\
\text { analyte }\end{array}$ & $\begin{array}{l}\text { Theoretical } \\
\text { content } \\
(\mu \mathrm{g} / \mathrm{mL})\end{array}$ & $\begin{array}{l}\text { Conc. found } \\
\mu \mathrm{g} / \mathrm{mL} \pm \mathrm{SD}^{*}\end{array}$ & $\begin{array}{l}\text { Recovery } \\
(\%)\end{array}$ & $\begin{array}{l}\text { RSD } \\
(\%)\end{array}$ & SEM \\
\hline 50 & 6 & $6.06 \pm 0.0575$ & 100.98 & 0.9484 & 0.0332 \\
100 & 8 & $8.03 \pm 0.0475$ & 99.7 & 0.5958 & 0.0274 \\
150 & 10 & $9.99 \pm 0.0698$ & 99.32 & 0.7023 & 0.0403 \\
\hline
\end{tabular}

* Average of three determinations. 


\section{Determination of absorption maxima}

Standard solution $(10 \mu \mathrm{g} / \mathrm{mL})$ approximately $3.0 \mathrm{~mL}$ was taken and scanned from 200 to 400 $\mathrm{nm}$ with fixed slit width of $2.0 \mathrm{~nm}$. The methanol was used as blank.

\section{Calibration curve}

The calibration curve was constructed by analyzing five different concentrations of standard solution $(6.0-14.0 \mu \mathrm{g} / \mathrm{mL})$, prepared on the same day. All determinations were conducted in triplicate.

\section{Preparation of sample solutions}

For analysis of marketed formulations, twenty tablets were accurately weighed and powdered. The powder equivalent to $2.0 \mathrm{mg}$ of glimepiride weighed accurately and transferred to $10 \mathrm{~mL}$ volumetric flask containing $1.0 \mathrm{~mL}$ of $0.1 \mathrm{M} \mathrm{NaOH}$. The mixture was sonicated to dissolve, make up the volume with methanol and filtered through a $0.45 \mu \mathrm{m}$ membrane filter. Aliquots of these standard solution was transferred using A-grade bulb pipettes into $100 \mathrm{~mL}$ volumetric flasks and the solutions made up to volume with methanol to give final concentration of $10 \mu \mathrm{g} / \mathrm{mL}$. The above solution was then analyzed for the content of glimepiride using the proposed method.

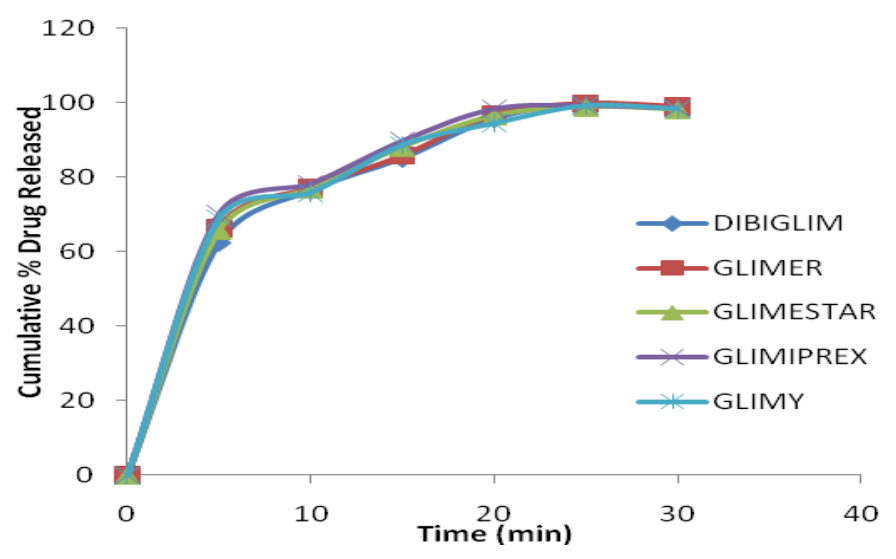

Figure 3. Dissolution profile of different brands of glimepiride tablets.

Table 3. Assay results of glimepiride in tablet dosage forms.

$\begin{array}{ll}\text { Tablet Dosage Form } & \begin{array}{l}\text { Label Claim } \\ \mathrm{mg} / \mathrm{tab}\end{array} \quad \% \text { Label Claim } \pm \mathrm{SD}^{*}\end{array} \quad$ RSD (\%)

\begin{tabular}{llll}
\hline DIBIGLIM & 2 & $99.57 \pm 0.5917$ & 0.5943 \\
GLIMER & 2 & $100.36 \pm 1.8546$ & 1.8479 \\
GLIMESTAR & 2 & $100.14 \pm 0.3419$ & 0.3414 \\
GLIMIPREX & 2 & $100.19 \pm 1.2758$ & 1.2734 \\
GLIMY & 2 & $99.86 \pm 0.3627$ & 0.3632 \\
\hline
\end{tabular}

*Average of six determinations. 


\section{Dissolution Studies of glimepiride tablets}

The dissolution studies of glimepiride tablets were performed on a paddle-stirrer type of apparatus. The dissolution studies were performed according to dissolution procedure recommended for single-entity products in $900 \mathrm{~mL}$ of $\mathrm{pH} 7.8$ phosphate buffer $(75 \mathrm{rpm})$. The temperature of the cell was maintained at $37 \pm 0.5{ }^{\circ} \mathrm{C}$ by using a thermostatic bath. At each sample time interval, an exact volume of the sample was withdrawn from each flask and immediately replaced with an identical volume of fresh medium to maintain a dissolution sink conditions. At predetermined time intervals $(0,5,10,15,20,25$, and 30 $\mathrm{min}$ ) for the dissolution studies, and the proposed method was used to determine the concentration of glimepiride in dissolution medium. In order to obtain the dissolution profile, the cumulative percentage of drug released was plotted against time (min).

\section{Method Validation}

The method was validated according to International Conference on Harmonization (ICH) 2QB guidelines ${ }^{11}$ for validation of analytical procedure in order to determine the linearity, limit of detection, limit of quantitation, accuracy and precision.

\section{Results and Discussion}

Glimepiride was analyzed by developed UV spectrophotometric method in tablets. The UV spectrum (Fig. 2) shows absorption maxima at $225 \mathrm{~nm}$. The calibration curve showed linearity over a concentration range from $6.0-14.0 \mu \mathrm{g} / \mathrm{mL}$, which follows the Beer and Lambert's law. The correlation coefficient of the curve obtained with linear regression method was 0.9993 . The linear regression data for the calibration plot is indicating of a good linear relationship between absorbance and concentration over a wide range. The correlation coefficient was indicative of high significance. The low value of intercept of the ordinate showed the calibration plot did not deviate from linearity. The LOD and LOQ values were found to be $0.06 \mu \mathrm{g} / \mathrm{mL}$ and $0.17 \mu \mathrm{g} / \mathrm{mL}$, respectively. The recovery was assessed from three replicate determinations of three different solutions containing $6.0,8.0,10.0 \mu \mathrm{g} / \mathrm{mL}$. The absolute means obtained were 100.98, 99.7, and $99.32 \%$ respectively as shown in Table 2. It is evident that the method is accurate within the desired range. The precision of the method was checked by carrying out six independent assays of glimepiride test samples against a working standard. Intermediate precision was checked by analyzing the samples by two different analysts using same instrument. The lower percentage RSD $(<2.0 \%)$ values shows that the method is more precise. The developed method was applied to the quantification of glimepiride in tablets available in local market. The results were tabulated in Table 3. It can be seen that, the results obtained by proposed method was very much similar to that of established methods. Dissolution studies of different brands of glimepiride tablets by proposed method reveal that more than $75 \%$ of labeled amount is dissolved within 15 min, which is correlating with IP method. As per IP, the assay and dissolution studies of glimepiride tablets were done by using liquid chromatography, where as the advantage of this method can be used for both assay and dissolution studies of glimepiride in tablets.

\section{Conclusion}

The proposed method is rapid, accurate, precise and sensitive for the quantification of glimepiride from its pharmaceutical dosage forms. The method rely on the use of simple working procedure comparable to that achieved by sophisticated and expensive technique like HPLC, and hence this method can be routinely employed in quality control for analysis of glimepiride in tablets and dissolution studies. 


\section{Acknowledgement}

The authors are grateful acknowledge the receipt of pure glimepiride from Matrix Laboratories Ltd, Hyderabad, India.

\section{References}

1. Langtry HD and Balfour JA, Glimepiride: A review of its use in the management of type 2 diabetics, Drugs, 1998, 55, 563-84.

2. Khan IU, Aslam F, Ashfaq M, Asghar MN, Determination of glimepiride in pharmaceutical formulations using HPLC and first-derivative spectrophotometric methods, J. Anal. Chem., 2009, 64(2), 171-5.

3. Wanjari DB and Gaikwad NJ, Reversed phase HPLC method for determination of glimepiride in tablet dosage form, Indian J. Pharm. Sci., 2005, 67(2), 251-5.

4. Altinoz S and Tekeli D, Analysis of glimepiride by using derivative UV spectrophotometric method, J. Pharm. Biomed. Anal., 2001, 24(3), 507-15.

5. Salem II, Idrees J, Jaafar I and Tamimi AI, Determination of glimepiride in human plasma by liquid chromatography-electrospray ionization tandem mass spectrometry, J. Chromatogr. B., 2004, 799(1), 103-9.

6. Shveta C, Kasture AV and Yeole PG, Simultaneous spectrophotometric determination of pioglitazone hydrochloride and glimepiride in tablets, Indian. J. Pharm. Sci., 2005, 67(5), 627-9.

7. Anju Goyal and Singhvi I, Simultaneous spectrophotometric estimation of rosiglitazone maleate and glimepiride in tablet dosage forms, Indian J. Pharm. Sci., 2007, 69(6), 7803.

8. Pawar SP, Meshram GA and Phadke MU, Simultaneous LC estimation of glimepiride and metformin in glimepiride immediate release and metformin sustained release tablets, Chromatographia, 2008, 68(11-12), 1063-6.

9. Praveenkumar RB, Boopathy D, Mathew B, Prakash M and Perumal P, Method development and validation of simultaneous determination of pioglitazone and glimepiride in pharmaceutical dosage form by RP-HPLC, Int. J. Chem Tech Res., 2010, 2(1), 50-3.

10. FDA 1997a. Center for Drug Evaluation and Research, Guidance for Industry: Dissolution Testing of Immediate Release Solid Oral Dosage Forms, August-1997.

11. International Conference on Harmonization (ICH) of Technical Requirements for the Registration of Pharmaceuticals for Human Use. Validation of Analytical Procedure: Methodology (ICH - Q 2B). 1996; November: 1-8. 


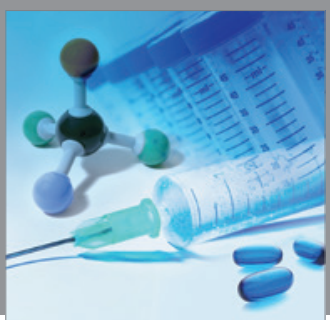

International Journal of

Medicinal Chemistry

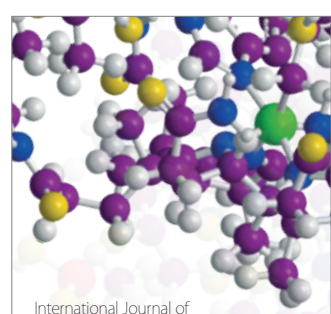

Carbohydrate Chemistry



The Scientific World Journal
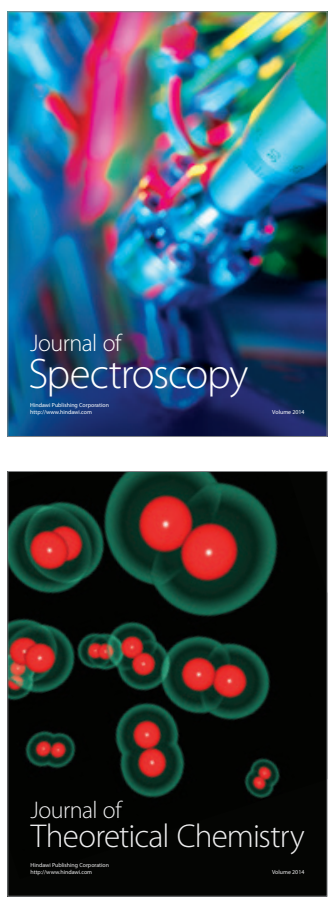
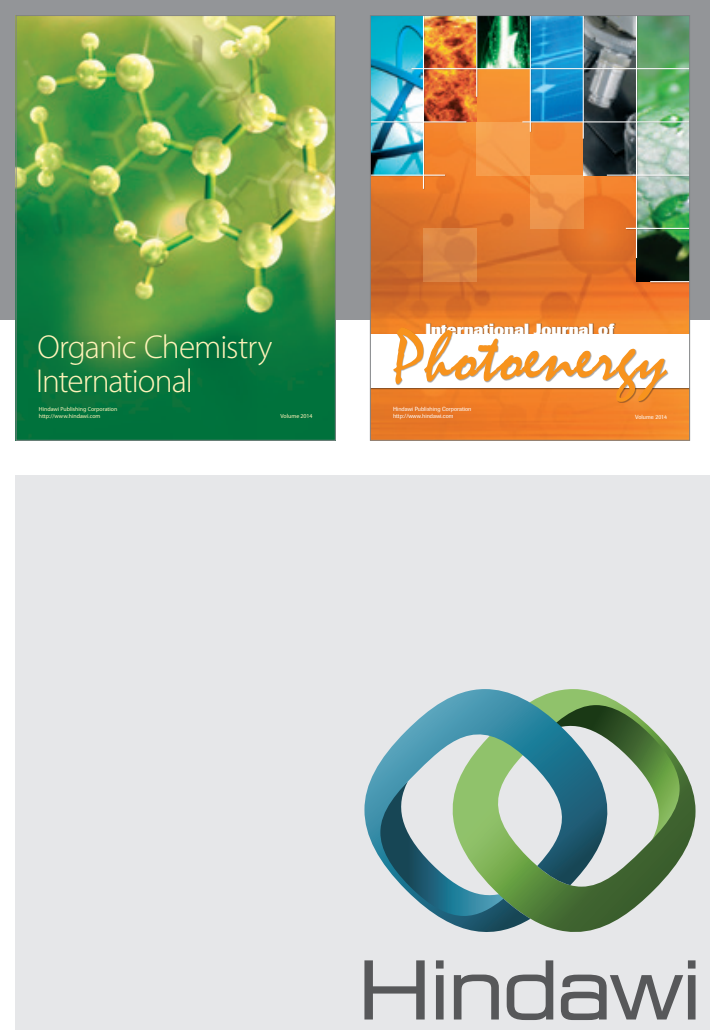

Submit your manuscripts at

http://www.hindawi.com
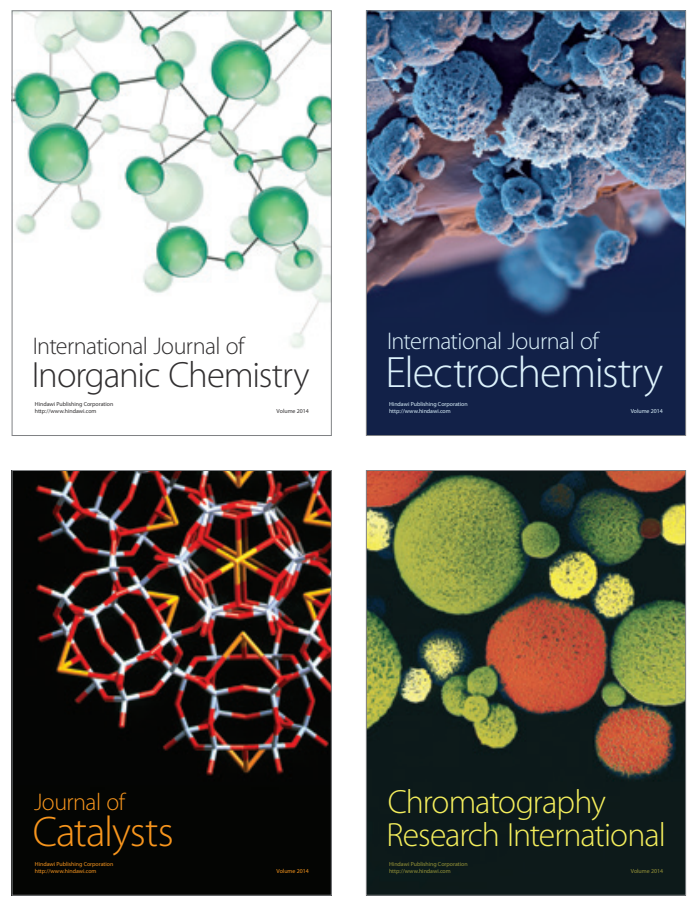
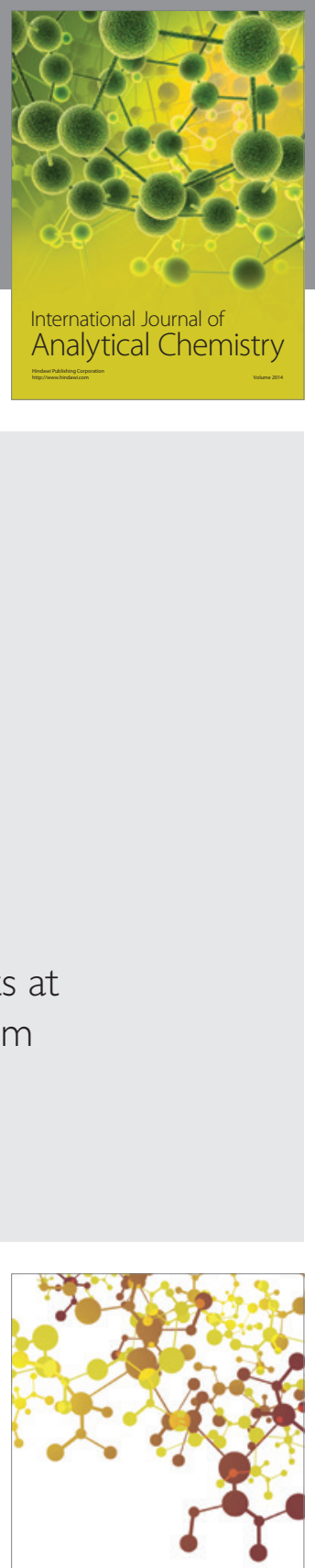

Journal of

Applied Chemistry
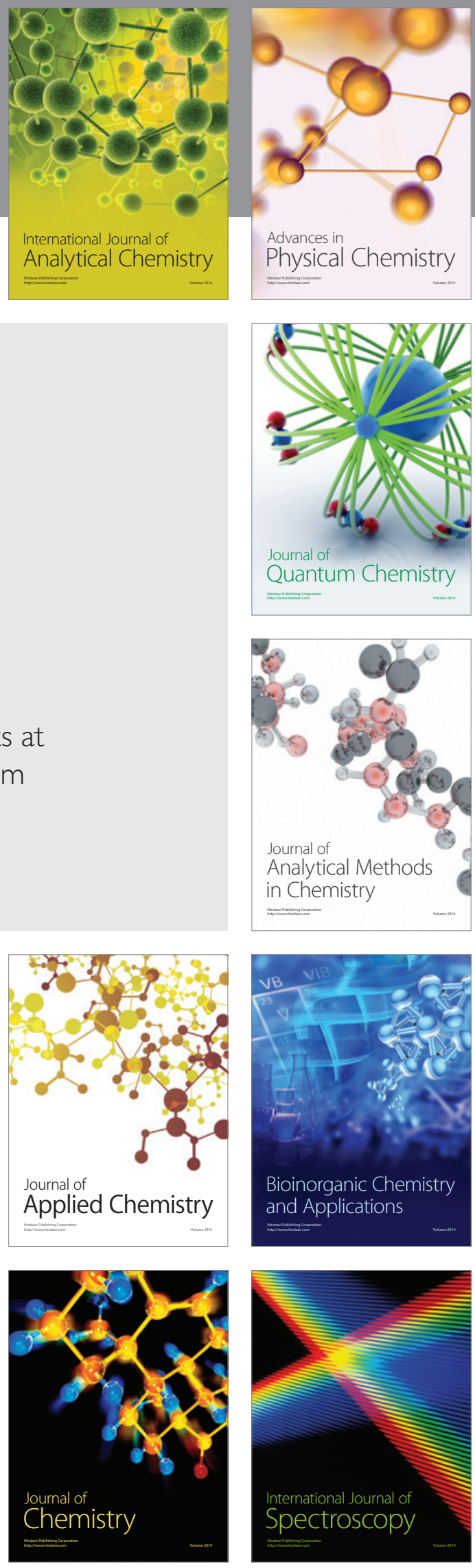